\title{
MOTIVOS GRIEGOS COMO MÉTODO COMPOSITIVO EN LA HISTORIETA SERENO DE LUCIANO VECCHIO
}

\author{
Greek Motifs as Composition Method in Luciano Vecchio's comic Sereno
}

\author{
Hernán Martignone* \\ Universidad de Buenos Aires \\ hmartignone44@gmail.com
}

Palabras clave

historieta;

Argentina;

Grecia antigua;

Sereno;

Luciano Vecchio

\section{Keywords}

comic;

Argentina;

Ancient Greece;

Sereno;

Luciano Vecchio

\begin{abstract}
Resumen
Construida en parte sobre el modelo narrativo del manga Sailor Moon y en parte sobre el cómic de superhéroes norteamericano, Sereno de Luciano Vecchio se presenta como una ficción original, de múltiples lecturas, en la que diversos elementos del mundo griego clásico encuentran su lugar. En el presente artículo me propongo analizar el funcionamiento de dichos elementos (míticos, lingüísticos, icónicos) como método compositivo de una obra con un carácter marcadamente multicultural. En la serie se suceden menciones o alusiones que abarcan desde la Titánide Teia (que da nombre a la ciudad y aparece como personaje mítico) hasta creaciones como Fotofobos, Pánico o Pathos, pasando por los pinups "Sirena" y "Épicx", por lo que entiendo que se trata de un principio constructivo de la ficción (presente en los títulos de los capítulos, en los personajes, en ideas puestas en narración), de esas tramas que Vecchio arma para reinterpretar el género superheroico como productor de "mitos modernos".
\end{abstract}

\begin{abstract}
Built partly upon the storytelling model of the Sailor Moon manga and partly on the American superhero comic, Sereno by Luciano Vecchio presents itself as an original fiction with multiple interpretations, in which different elements from the classical Greek world find their place. This article aims to analyze the way those elements -being mythical, linguistic or iconic- work as a composition method resulting in a markedly multicultural artwork. The comic series features -overtly or covertly- elements such as Titaness Theia (in the name of the city and as a mythical character), creations such as Fotofobos, Pánico, and Oneres, as well as the "Siren" or "Epic" pinups; which I understand to be a constructive principle of fiction (appearing in chapter titles, characters and storytelling ideas), of the plotlines that Vecchio crafts in order to reinterpret the superheroic genre as a producer of "modern myths".
\end{abstract}




\title{
Motivos griegos como método compositivo en la historieta Sereno de Luciano Vecchio
}

\author{
Quien ha sido pupilo del relámpago \\ aprende que el sentido \\ se aloja \\ en un fulgor. \\ Marisa Martínez Pérsico, "Arte didáctica”
}

'Serenidad' escrito en una lengua muerta... Gabo Ferro, "Sobre madera rosa"

En el presente artículo me propongo indagar la presencia y el uso de ciertos elementos míticos, lingüísticos e icónicos de la cultura griega antigua por parte del historietista Luciano Vecchio (Zárate, 1982) en el primer volumen de su obra superheroica Sereno (y brevemente en su continuación, Sereno $S$, donde vuelven a presentarse dentro del proceso creativo, y en dos pinups publicados online). ${ }^{1} \mathrm{Si}$ bien el autor no trabaja únicamente con la "recepción de materiales helénicos", ${ }^{2}$ sino que propone un sincretismo/eclecticismo empático entre varias culturas (multiculturalismo en sentido amplio), me concentraré en estudiar los distintos niveles en los que incide dicha influencia, muy productiva narrativamente y proveniente en parte del modelo propuesto en Sailor Moon (1991-1997). ${ }^{3}$ Allí, la mangaka Naoko Takeuchi abreva de la mitología grecorromana en las figuras de los dioses/planetas y en otras como la de Endimión (amante de Selene, "Luna" en griego). ${ }^{4}$ Por momentos, Sereno es una especie de palimpsesto en el que vemos rastros o trazos de ese célebre manga (el ritmo, ciertos efectos gráficos, el tipo de poderes desplegados). El nombre Sereno (al que volveré un poco más adelante) funciona en primer lugar como homenaje al que recibió el personaje de Usagi Tsukino (alter ego de Sailor Moon) en el doblaje americano, Serena, tomado del de la princesa Serenity en el manga (nótense la relación fónica con Selene y la referencia al "mare Serenitatis" del satélite terrestre).

1. Este trabajo se inserta en el proyecto FILO:CyT FC19-038 (2019-2021) "Representaciones y apropiaciones de la Antigüedad clásica en la historieta argentina", desarrollado en el marco del Programa de Apoyo a la Investigación de la Facultad de Filosofía y Letras de la Universidad de Buenos Aires y radicado en el Instituto de Filología Clásica de la misma Facultad. Una primera versión más breve de este texto fue expuesta en el III Congreso Universitario de Historietas (CUH), Facultad de Humanidades y Ciencias de la Educación, Universidad Nacional de La Plata, el 28 de noviembre de 2019. 2. Sobre la noción de "recepción” o de "recepciones", de carácter más dinámico que el concepto de "tradición" (García Jurado, 2015, p. 18-19), véanse Hardwick y Stray (citados en García Jurado, 2015, p. 28): "Por 'recepciones' nos referimos a las maneras en que la materia griega y romana ha sido transmitida, traducida, extractada, interpretada, reescrita, reimaginada y representada". Es claro a partir de lo anterior que "recepciones" se refiere no solo al reconocimiento de la presencia de ciertos elementos, sino también a la creación o a la reelaboración (en todo caso, una lectura reinterpretativa, creativa).

3. Esta obra fue publicada en la Argentina por la editorial Ivréa.

4. Véase al respecto, en general, Hernández Reyes (2008). 
Asimismo, los "actos" en los que se divide Sailor Moon son renombrados como "pulsos" en Sereno, con las diversas resonancias que esa palabra tiene en español. ${ }^{5}$

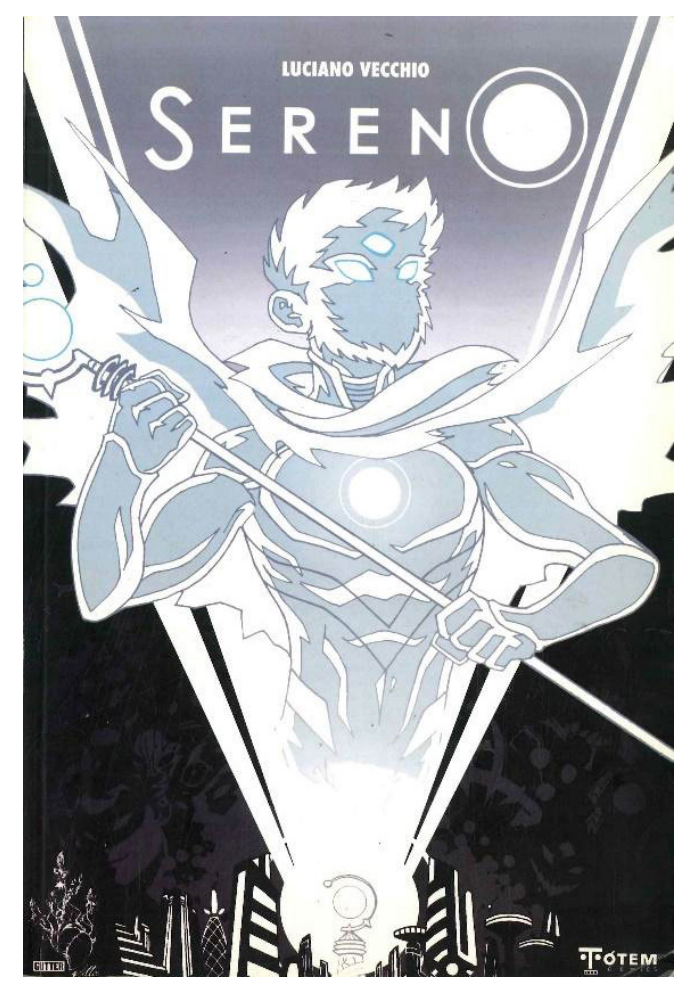

Figura 1. Vecchio, Sereno, 2016, tapa.

Sin embargo, Sereno es fundamentalmente una historieta de género superheroico, ${ }^{6}$ de raigambre norteamericana, que se produce en un contexto argentino y en el marco específico de la web Tótem Comics, ${ }^{7}$ dedicada a dicho género y llevada adelante por los historietistas Enrique Alcatena y Fernando Calvi (con la participación de otrxs autorxs). Además, cabe destacar que Vecchio escribe y dibuja cómics de superhéroes para las más renombradas editoriales de los Estados Unidos como son Marvel y DC. En este proyecto personal, en el que se encarga de todas las facetas creativas y presenta una impronta de deconstrucción de la figura del superhéroe ${ }^{8}$ desarrolla una línea que roza lo espiritual, aunque abunden los conflictos y las luchas, a los que siempre da una vuelta de tuerca (en general no violenta) a la hora de resolverlos.

5. Cfr. Diccionario de la lengua española $[D L E]$; véanse por ejemplo la acepción 3: "Seguridad o firmeza en la mano para ejecutar una acción que requiere precisión" (que podría interpretarse en términos de "serenidad") y la acepción 6: "Enfrentamiento entre dos partes equilibradas en sus fuerzas, que mantienen intereses o puntos de vista diferentes" (que podría ser un buen resumen del conflicto entre luz y oscuridad que recorre la serie).

6. Sobre el tratamiento de la "cuestión superheroica" en Sereno, véase el trabajo de Carrión (2017).

7. Sobre este proyecto y otras historietas argentinas contemporáneas que abordan lo superheroico, véase Hildebrandt (2019).

8. "Un superhéroe de impronta antipatriarcal" lo denomina Carrión (2017, p. 1). 
Con Sereno el autor logra, más allá de la influencia genérica mencionada, construir un personaje con identidad propia, verdaderamente icónico y potente. La conformación de su persona "civil" parte de un principio constructivo típico de los cómics de superhéroes (Carrión, 2017, p. 4): la aliteración presente en su nombre, Serafín Sourenian (como en Lois Lane o Peter Parker), en el que cada elemento es sumamente pregnante. Serafín significa, "en la tradición católica, cada uno de los espíritus celestes que forman su primer coro y, junto con los querubines y los tronos, la primera jerarquía, la cual contempla directamente a Dios y canta su gloria" $(D L E)$; no obstante, por calambur, puede leerse como "ser afín", según parece sugerirse hacia el final del pulso 7: "Lo genuino hace eco. Lo afín orbita en resonancia". ' Sourenian, por su parte, guarda ecos de "sereno" pero también de "sureño" (y de la forma de armar gentilicios como "Argentinean" o "Argentinian" en inglés), quizás en aliterativa alusión a nuestra América del Sur, a nuestro "sudor sudaca" argentino. La unidad intrínseca de Serafín y de su alter ego -o habría que decir alert ego, ego alerta, en consonancia con el popular relato zen "Conciencia constante"-, Sereno, se ve en la repetición de esas tres significativas letras iniciales, que es además el hipocorístico con el que no casualmente lo llaman sus amigos (“Ser”).

En español, "sereno" se revela como un término con múltiples resonancias, según puede apreciarse en la entrada léxica correspondiente del DLE:

sereno, na (Del lat. serēnus)

1. adj. claro (despejado y sin nubes).

2. adj. Apacible, sosegado, sin turbación física o moral.

3. adj. Dicho de una persona: Que no está bajo los efectos del alcohol. Estar sereno.

4. m. Humedad de que durante la noche está impregnada la atmósfera.

5. m. Encargado de rondar de noche por las calles para velar por la seguridad del vecindario, de la propiedad, etc.

6. m. Ec. Serenata, música nocturna y al aire libre para festejar a alguien.

7. m. Perú. Vigilante del serenazgo [Servicio municipal de vigilancia y seguridad pública].

8. f. Composición poética o musical de los trovadores, que solía cantarse de noche.

9. f. coloq. Humedad de la atmósfera en la noche.

a la serena

1. loc. adv. coloq. al sereno.

al sereno

1. loc. adv. A la intemperie de la noche.

Más allá del señalado juego con el nombre Serafín, Sereno propone una riqueza mucho mayor (en el plano del significado y del significante $)^{10}$ que los sinónimos propuestos en la acepción 2 como "apacible" o "sosegado", y otros que podrían agregarse, como "calmo" o "tranquilo", amén de que como sustantivo común (acepción 5) designa una especie de "guardián” (acepciones 5 y 7), como dice el propio personaje al comienzo de la historia: "La noche necesita un sereno. Soy el Sereno. Soy el guardián que deambula por la noche”. ${ }^{11}$ En el final del primer volumen, ante la pregunta “¿Cómo te

9. Además, "Sera" es la romanización del término japonés que designa a "Sailor" en el título Pretty Guardian Sailor Moon: Bishōjo Senshi Sèrā Mūn.

10. Juegos con palabras como Sirena u Oneres, como veremos más adelante.

11. Como vimos arriba, el título completo con el que suele conocerse Sailor Moon incluye la palabra guardian. 
sentís?”, Serafín responderá: “De la mejor manera. Me siento Sereno” (jugando con su nombre heroico y con la acepción 2, "sin turbación física o moral"). ${ }^{12}$ También la primera acepción ("claro") y la cuarta, referidas a fenómenos meteorológicos, apuntan a las ya comentadas resonancias "celestes" presentes en Sailor Moon.

Antes de pasar al análisis propiamente dicho de la historieta, me parece una curiosidad pertinente relacionar esas últimas acepciones con un término griego que vincularé con la palabra española "sereno": fue utilizado en la obra Relatos verídicos por el escritor Luciano de Samósata (s. II d. C.) para componer el nombre de un personaje que podría considerarse un antecedente de Sereno. ${ }^{13}$ El término en cuestión es el sustantivo ev̉oía (eudía), que el diccionario oxoniense de Liddell, Scott y Jones $[L S J]$ define con las acepciones "fair weather" (y su variante "fine weather") y "tranquillity, peace". El clásico diccionario griego-español Vox, a cargo del excatedrático y traductor español José M. Pabón, brinda los siguientes significados: "Buen tiempo, tiempo sereno, calma [en el mar]; calma, serenidad de espíritu”. En Relatos verídicos, considerada la primera obra de ciencia ficción (paródica, aunque el género aún no existiera), se cuenta una guerra entre la Luna y el Sol, cuyos reyes son respectivamente Endimión y Faetonte ("Resplandeciente", "Radiante"). Allí, cuando se describe el ejército de la Luna,

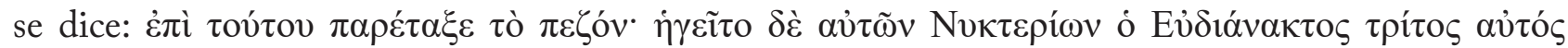
(1.15.10-11). Espinosa Alarcón (1981, p. 186-187) traduce de la siguiente manera: "Alineó en ésta a la infantería, a las órdenes de Nocturno (Nykterion), hijo de Sereno (Eudiánax), y otros dos jefes”. Y,

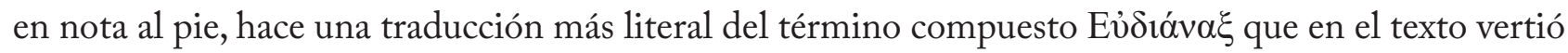
como Sereno: "Soberano [ánax] del tiempo sereno [eudia]". ${ }^{14}$ Eudiánax (o Eudianacte), entonces, aunque exista solo en esa mención como padre de Nocturno, podría constituir el arquetipo (perdido y encontrado) del superhéroe de Vecchio.

\section{Historia de dos ciudades (en una)}

Sereno comienza con la ubicación espacial de la acción en Nueva Teia [FIG.1] y ese topónimo (las primeras palabras que se leen en la historieta) y esa referencia al mito griego marcarán en gran medida (junto con otros elementos) todo el desarrollo de la serie, como intentaremos mostrar a continuación. El

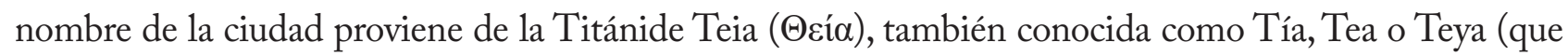
será explícitamente mencionada e ilustrada en la historieta, como veremos). Sus menciones más antiguas se hallan en Hesíodo (Teogonía vv. 135 y 371-374), ${ }^{15}$ y aparece en el "Himno homérico a Helios" (el Sol) con el nombre de Eurifaesa (Eủ indisociablemente unida a la idea de luminosidad. ${ }^{16}$ Grimal (1999, p. 514) la presenta así:

12. Interesantes resultan también las acepciones 6 y 8 , que remiten a creaciones poéticas interpretadas de noche.

13. Antecedente involuntario, ya que Vecchio contó, cuando lo invité a hablar sobre su obra en el seminario de extensión universitaria "Mitos griegos en la historieta argentina" que dicté en 2017 (Facultad de Filosofía y Letras, UBA), que nunca había tenido noticias del personaje del autor samosatense.

14. En $L S J$ se define esta palabra como "ruler of the calm".

15. Uno de los personajes secundarios que trabaja en la Universidad Akáshica se llama Alba y es presentada como "neuróloga y bruja ensoñadora" (pulso 2).

16. Grimal (1999, p. 514) agrega otras fuentes: el recopilador Apolodoro, Biblioteca I, 1, 3; 2, 2; y Píndaro, "Ístmica V", v. 1, que veremos a continuación. Cfr. el "Himno homérico a la Luna”, donde se destacan las propiedades lumínicas del astro nocturno. 
Tía, la Divina ${ }^{17}$ pertenece a la primera generación divina, anterior a los Olímpicos. Es una de las Titánides, hija de Urano y Gea. Uniose a Hiperión, de quien tuvo tres hijos: Helios (el Sol), Eos (la Aurora) y Selene (la Luna).

Este linaje está relacionado íntimamente con la luz en diferentes aspectos, al igual que el propio personaje de Sereno (a quien en la historieta se llama "ser de luz") y la mayoría de las aventuras que vive (siempre fluctuando entre la luz y la oscuridad), así como los diversos poderes que despliega ("lluvia de fotones", "chispa de conciencia", "pulso radiante", "pilar de luz" o "fulgor supremo"). Sereno es, entre muchas otras cosas, una gran historieta sobre la iluminación o las iluminaciones posibles, sobre la tensión entre el día y la noche, entre la luz y la oscuridad, y Nueva Teia es el escenario donde ese encuentro tiene lugar. ${ }^{18}$

En Píndaro (“Ístmica V”, vv. 1-6), por su parte, la Titánide es presentada como dadora de luz a todas las cosas:

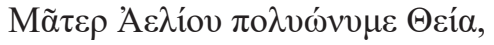

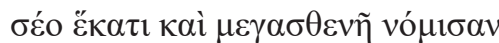

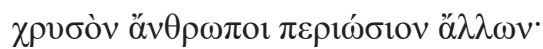

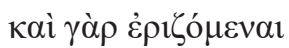

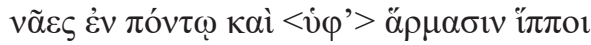

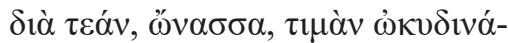

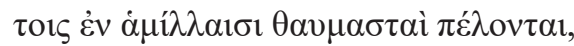 \\ Madre de Helios, de múltiples nombres, Teya, \\ por ti consideran también de gran fuerza \\ los hombres el oro, por encima de todas las cosas. \\ Pues también disputando \\ las naves en el mar, y con carros las yeguas \\ por tu honra, oh soberana, son admirables \\ en los vertiginosos certámenes. ${ }^{19}$
}

Como señala Ortega (1984, p. 292), su nombre puede tener dos significados: "Significa 'la que mira y contempla' ([del verbo] theáomai) o bien 'la Divina' (theia)", y explica que "tiene innumerables nombres porque ve todo y hace que todo pueda verse en ella”, pero esta multiplicidad onomástica sugiere también una serie de asimilaciones con otras diosas como Febe (Фoí $\beta \eta)$, "la Brillante", hija de Urano y Gea (y abuela, o madre, de Febo Apolo), homónima de una de las Helíades (hijas del Sol). Un poco más adelante volveré sobre esta cuestión, pero puede pensarse que "Nueva Teia" implica una

17. Ese es el significado literal del adjetivo griego del que deriva el nombre, pero veremos que puede interpretarse también de otra manera.

18. Sánchez Kutika (2016, p. 1) describe Nueva Teia como "ciudad capaz de albergar en su seno tanto la luz más virtuosa como la oscuridad más profunda". Sobre esa tensión, véanse las primeras tres páginas de Sereno, especie de "proemio" de los pulsos que vendrán.

19. Las traducciones de textos griegos me pertenecen a menos que se indique lo contrario. 
"nueva luz" o una "nueva mirada", alejada justamente de la idea de la diosa que da brillo al oro o a las piedras preciosas, representación de lo material (frente a lo espiritual).

Además de ser una divinidad primigenia, a menudo olvidada, durante la Titanomaquia (la batalla entre los Titanes y los Olímpicos comandados por Zeus) permaneció neutral, lo cual habilita su caracterización como una diosa pacífica o pacifista. ${ }^{20}$ Ello le evitó el castigo al que fueron sometidos los Titanes derrotados: la reclusión en el Tártaro, mundo subterráneo y muy profundo, debajo incluso del Hades, asociado con la muerte y con la oscuridad. El calificativo "Nueva" habla, por un lado, de una relectura del personaje mítico -aunque sigue siendo una divinidad, protectora de los habitantes y garante de la luz, una suerte de Atenea para la polis de Atenas-, pero también de "traerla a la luz", de hacerla visible nuevamente. De hecho, el nombre de la ciudad es destacado por el tamaño de la tipografía, mayor que el usado habitualmente en los captions o "cartuchos" de texto de la obra [FIG.2].

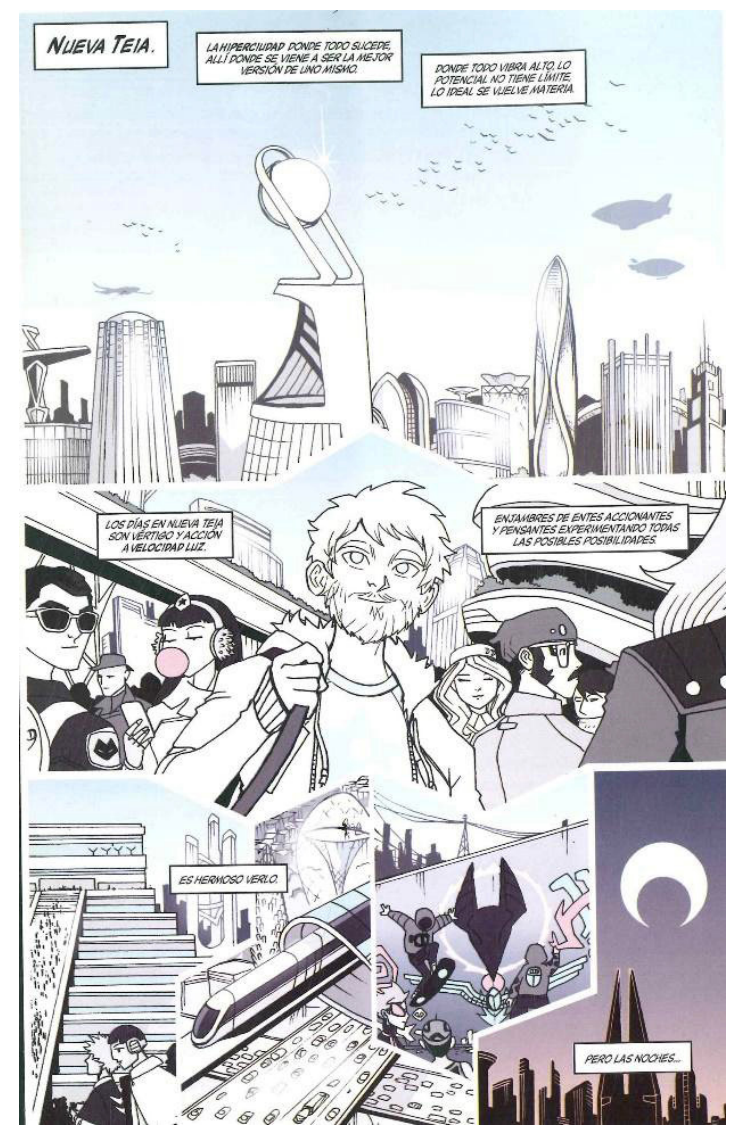

Figura 2. Vecchio, Sereno, 2016, p. 6.

La anterior mención de Atenas no era ociosa, ya que Nueva Teia se describe como "una hiperciudad donde todo sucede, allí donde se viene a ser la mejor versión de uno mismo. Donde todo vibra alto, lo potencial no tiene límite, lo ideal se vuelve materia" (pulso 1). Es, verbal y gráficamente -como se aprecia en el primer cuadrito de la historieta [FIG.2]-, una utopía, y la citada descripción

20. Ese pacifismo está muy en sintonía con la tónica no violenta que emana de Sereno. 
recuerda en gran medida las palabras que Pericles dedica a Atenas en el célebre discurso fúnebre transmitido por Tucídides (II. 35-46), en el que la ciudad griega es presentada en gran medida como una utopía realizada. Este "organismo viviente" (pulso 1) se muestra como una nueva Atenas, pujante y llamativa, que casi obliga a que posemos sobre ella nuestra mirada (como la Urbs en la "Bucólica I de Virgilio": et quae tanta fuit Romam tibi causa videndi?, v. 27), ${ }^{21}$ un centro de atracción cultural profunda al que llegará Serafín Sourenian (Sereno) a los veinte años, becado por la Universidad Akáshica ${ }^{22}$ (doble decisión que ya había tomado a los once: estudiar Astrofísica y vivir en la "gran” ciudad, en la "ciudad luz”). Sin embargo, también tiene sus sombras y su costado más oscuro, como señala el personaje de Rufián (pulso 3), que habita en Demimundo, resabios de Teia antigua: "La utopía luminista no es para todos, Sereno. Están los que no encajan y los que no queremos encajar. Y somos un montón” ${ }^{23}$

\section{Fiat lux!}

Vecchio, por lo demás, incluye al personaje mítico Teia en la historieta. La referencia abarca la tercera tira de la primera página del pulso 7 (titulado "Serendipia"), ${ }^{24}$ que tiene cuatro viñetas [FIG.3]. En el primer cuadro se ve una suerte de "Sereno griego" 25 (por el atuendo, el paisaje montañoso y la arquitectura típica de la Grecia antigua, presentados de manera minimalista) y en el recuadro de texto se lee: "Milenios ha, los ojos emiten un haz de luz que permite ver aquello que alcanza. Un rayo de visión". Esta idea, que circulaba efectivamente en el mundo griego, sirve de inspiración "científica" para varios de los poderes lumínicos de Sereno. En el siguiente cuadrito, junto a la representación gráfica de la Titánide, ${ }^{26}$ tenemos su mención explícita: “Teia es la diosa titánide de la visión y de la luz, madre del sol y la luna". ${ }^{27}$

21. “¿Y qué razón tan grande tuviste para ver Roma?”. La respuesta, en el verso siguiente, será "Libertas".

22. Esta universidad es descripta como "La vanguardia en conocimiento unificado, donde ciencia, filosofía y espiritualidad se reencuentran para potenciar las mentes más brillantes del mundo presente”. El término akáshico proviene de la tradición hindú.

23. Rufián es una suerte de homenaje masculino a Catwoman (Gatúbela), ambiguamente héroe y villano, que posee el poder del "ronroneo holístico" (y del encanto) y constituye el interés "romántico" de Sereno.

24. Además de la semejanza sonora entre Sereno y Serendipia, el autor se sirve de este concepto ("Hallazgo valioso que se produce de manera accidental o casual", $D L E$ ) para mostrar -con una distribución que rompe el orden habitual de la secuencia narrativa y de su lectura, como viñetas arrojadas al azar en la unidad que conforma una página y la utilización del "presente histórico" para narrar distintos momentos de la vida del personaje- una serie de eventos que pueden parecer más o menos azarosos; a la vez, sigue realizando su sincretismo cultural, en este caso con una fábula de origen oriental ("Los tres príncipes de Serendip") que cruza el mundo científico y el arte, como la propia serie Sereno y el microepisodio de Teia. 25. A quien podríamos bautizar Eudiánax o Eudianacte, según vimos.

26. Ya en el pulso 5 (“Umbral”) aparecía la estatua de la diosa [FIG.4].

27. La aparición explícita, desde lo verbal y desde lo visual, del personaje evitaría (no por tratarse de algo negativo) aquello que García Jurado (2015, p. 29) describe como "tradición no figurativa" al hablar de una pieza teatral inspirada muy libremente en una de Eurípides: "Podemos estar ante un caso de lo que cabría denominarse como 'Tradición no figurativa', dado que la forma de la obra moderna resalta tanto que oculta la materia antigua. No obstante, si gracias a esta perspectiva discurrimos desde las obras modernas hasta las antiguas, nos encontramos con la paradoja de cómo hay aspectos de la Antigüedad que hoy día llegan al gran público por medio de manifestaciones artísticas consideradas como 'periféricas'. Así ocurre con ciertos cómics inspirados en la Antigüedad". Uno de los mejores ejemplos de recepción creativa respecto de la Antigüedad puede verse en la serie de historietas Socrate le demi-chien (Sócrates el semiperro), de los franceses Joann Sfar y Christophe Blain. 

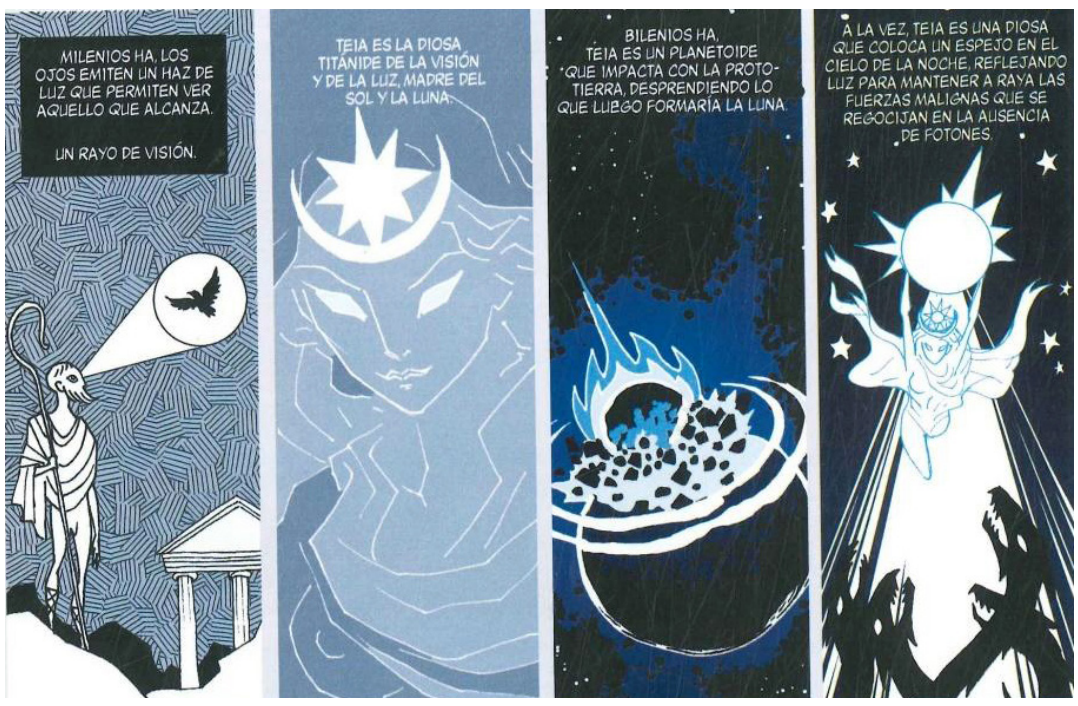

Figura 3. Vecchio, Sereno, 2016, p. 94.

La teoría de los "rayos visuales" (teoría de la emisión o de la extromisión) ha sido postulada y defendida por filósofos griegos antiguos como Empédocles y Platón. Márquez (2005, p. 116) explica su significación:

Según los historiadores de la mirada, la Grecia antigua representa una "era escópica" [del verbo skopein, "mirar"], en cuyo régimen la vista es experimentada como un órgano trans-ocular que irradia de la pupila para agarrar un objeto, para fundirse con él, y ese ojo se tiñe de los colores de las cosas (cf. Illich, 1993b). La noción de la mirada que no se implica en lo que ve y que toma distancia era desconocida para los griegos. El ojo no era un receptor pasivo de las imágenes, sino que interactuaba con lo observado. Quien mira "palpa". Ops y opsis designan la percepción visual, que se entiende como "rayo visual". (...) La mirada iluminaba los objetos y, de hecho, al igual que en el antiguo Egipto, los griegos concebían el sol como un gran ojo, que arroja la luz que nos permite ver las cosas. (...) Mirar es establecer contacto con lo mirado, y es por ello que, en este régimen escópico, no se concibe la "mirada objetiva", sino que se trata de una mirada que permea los objetos vistos. No hay observador neutral.

Esta idea puede encontrarse puesta en narración gráfica con la aparición del Selenita ${ }^{28}$ en el pulso 6 ("Fotofobia"), ya presentado sutilmente en pulsos anteriores, quien parece observar todo desde la distancia, "retirado del torrente tridimensión", aunque se aclara que "su tacto asiste el devenir" (notemos aquí la relación con la idea de que "la mirada palpa” y su realización gráfica: tanto Sereno como el Selenita tienen un "ojo" en cada mano). ${ }^{29} \mathrm{Y}$ en el pulso siguiente interviene directamente en la acción: "Mi yo superior, el Selenita, me asiste en este plano". Pero ya el propio Sereno se implica constantemente en lo que ve.

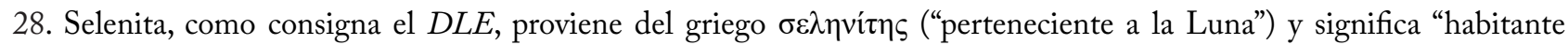
imaginario de la Luna" (cfr. LSJ: "oi $\Sigma \varepsilon \lambda \eta v i \tau \alpha$ the men in the moon", en el ya mencionado Relatos verídicos, 1.18, de Luciano de Samósata).

29. Asociado, al parecer, con la emisión de su "pulso radiante". 
En el tercer cuadro de la escena mencionada [FIG.3], se da un interesante cruce entre este mito y la ciencia astronómica: "Bilenios ha, Teia es un planetoide que impacta con la proto-Tierra, desprendiendo lo que luego formaría la Luna". Esto remite a la "hipótesis del gran impacto", que plantea que la Luna se formó cuando un protoplaneta chocó contra la Tierra y dio origen a lo que sería su satélite. El nombre del protoplaneta responde justamente a la mitología en tanto Teia es considerada la madre de la Luna (Selene). De ahí se deriva la idea expuesta en el cuarto cuadro de la tira [FIG.3]: "A la vez, Teia es una diosa que coloca un espejo en el cielo de la noche, reflejando luz para mantener a raya las fuerzas malignas que se regocijan en la ausencia de fotones".

En relación con esto, en el pulso 5 ("Umbral", que da la idea de sombra y de pasaje), el enemigo al que Sereno debe enfrentar se llama Espejo Negro (¿referencia a la serie televisiva Black Mirror, que como Sereno cruza tecnología y humanidad de una forma particular?) y se presenta con estas palabras: "La sombra anida en el abismo de las almas todas. Y mi cristal descascara la apolínea mascarada que la contiene. ¡Véanse en mí! ¡En mi fiesta de tinieblas no hay moral! Nadie es inocente. Todos tienen un lado oscuro". La oscuridad provoca la falta de moral, porque la mirada, al "tomar las cosas", implica "una moralidad debido a la imposibilidad de ser indiferente ante el mundo" (Márquez, 2005, p. 117). La idea de quitar la "máscara apolínea" remite al dios Apolo, también conocido como Febo (nombreepíteto derivado del adjetivo poĩßos, "brillante, radiante, puro"), que de hecho tenía su costado oscuro (como causante de pestes, por ejemplo). Eso podrá verse aplicado a Sereno, a quien Espejo Negro, a través del "reflejo obsidiana", revelará su otro yo dark, Oneres -inversión exacta de Sereno, con reverberaciones "oníricas": óneiros (őveipos) es "sueño" en griego-; como la criatura reconoce, "la luz más brillante proyecta la sombra más intensa”.

La mención de Apolo, no obstante, tiene otras resonancias que pueden vincularse con la mirada y con lo dicho acerca de Teia:

Para los griegos, ver algo implicaba dolor o placer. Así es como encontramos a Aristóteles hablando de "dolor en la mirada" (Retórica 1387b). Ver que al otro le va bien, que el otro posee algo que creemos necesitar, son situaciones que provocan envidia. No toda la fortuna conlleva sentimientos de envidia. También puede haber admiración por el bien de los demás. A esto se referían los griegos con el término "mirada armoniosa", atribuida a Apolo. (Márquez, 2005, p. 116)

Por eso, sin esa "mascarada apolínea", "Sereno tiene la consistencia de un susurro, de un rumor, de un mito urbano. Pero Oneres se presenta sólido a la vista de todos": el triunfo de una "mirada oscura". Este ser oscuro, de hecho, ha provocado un evento que convoca la atención de la gente de la ciudad: "Hasta la estatua de la diosa [Teia] ha sido vandalizada y todo el mundo se está acercando a ver” [cfr. FIG.4].

Sin embargo, por medio de la "absorción empática" (otro de sus poderes), Sereno termina aceptando esa parte de sí. Dentro de la ya comentada polisemia del nombre Sereno podríamos destacar -por medio de un anagrama, en este pulso de transformación y fusión- el sentido de "Neo Ser", que se resumiría muy bien en estos versos de la canción "Puesto a germinar" de Gabo Ferro (2016): 
Lo que ves no es lo que soy

ni fui,

hoy soy cuerpo puesto a germinar,

un preludio de tu nombre,

un rumor dulce de la oscuridad.

Cuando en el pulso 6 Sereno esté atrapado y no pueda usar sus "poderes fotónicos", recurrirá a Oneres, esa otra faceta o dimensión "oculta" de su ser, porque -dice el personaje- "la naturaleza de la luz es compleja. Y la mía también".

\section{Conceptos y personajes ("serenografía”; cfr. selenografía)}

También en ciertos conceptos y en otros personajes secundarios desarrollados por Vecchio se da la utilización del imaginario griego como principio constructivo de la ficción. En cuanto a los conceptos (inventados o tomados de diferentes ámbitos, como el científico), muchos de ellos presentan elementos o formantes léxicos griegos y son términos compuestos (típicos de esa lengua) que pueden estar en posiciones destacadas como los títulos de los pulsos (tres y medio de un total de siete: Parasomnia, ${ }^{30}$ ailurofilia, teofanía ${ }^{31}$ y fotofobia) o funcionando como ideas de ciencia (y de ficción): nube noósfera, absorción empática, condensador etérico, campo morfeogenético (variante parónima del concepto biológico efectivamente existente "campo morfogenético"), ${ }^{32}$ asimilación egrégora (relacionado con el ocultismo), mascarada apolínea, rayo selenita. Es llamativo el uso de palabras de raíz griega como adjetivos, que podría explicarse como una expansión y, por ende, un aporte de originalidad a los conceptos a los que modifican.

30. Construido lexicalmente como híbrido griego-latín $\left(\pi \alpha \rho \alpha^{-}+\right.$somnium $)$pero a imitación de términos compuestos griegos como paradoja o paranoia, su sentido sería "al lado del sueño" o quizás "pesadilla".

31. En este cuarto pulso se habla del Proyecto "nümen", que por juego fónico remite al concepto latino de numen (divinidad; cfr. sus significados en español en el $D L E$ ) y al sintagma inglés new men.

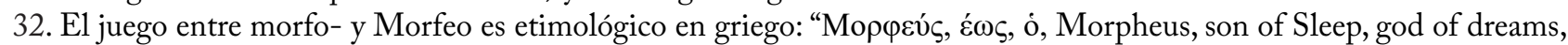

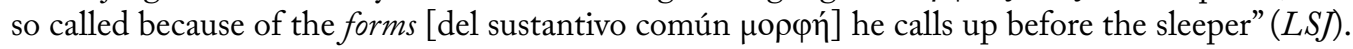




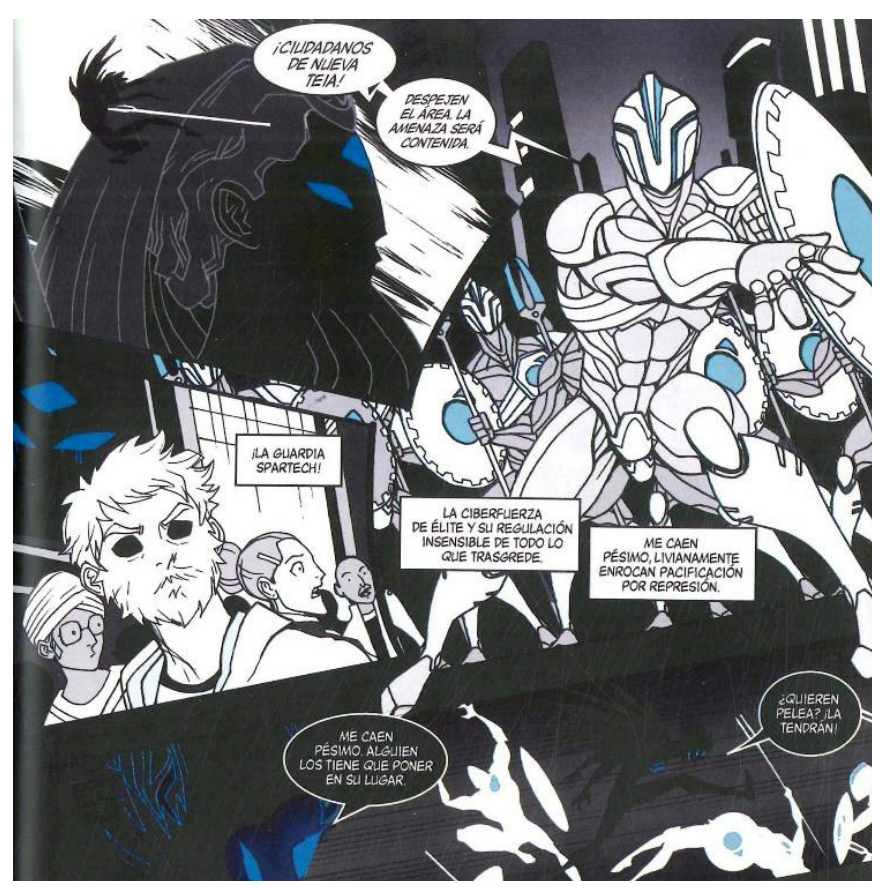

Figura 4. Sereno, Vecchio, 2016, p. 71.

Algunos de los mencionados términos -como el propio concepto de Selenita, astrofaro, condensador etérico o guardia spartech [FIG.4] (una "ciberfuerza de élite", una especie de robots de inspiración espartana por su carácter belicoso y por su armamento)- se materializan en dibujos, pero otros son "ideas" conceptuales (verbales) que constituyen núcleos que impulsan la acción, siempre en contacto con términos pertenecientes a otras culturas (cintamani, chakras, akáshico, etc.).

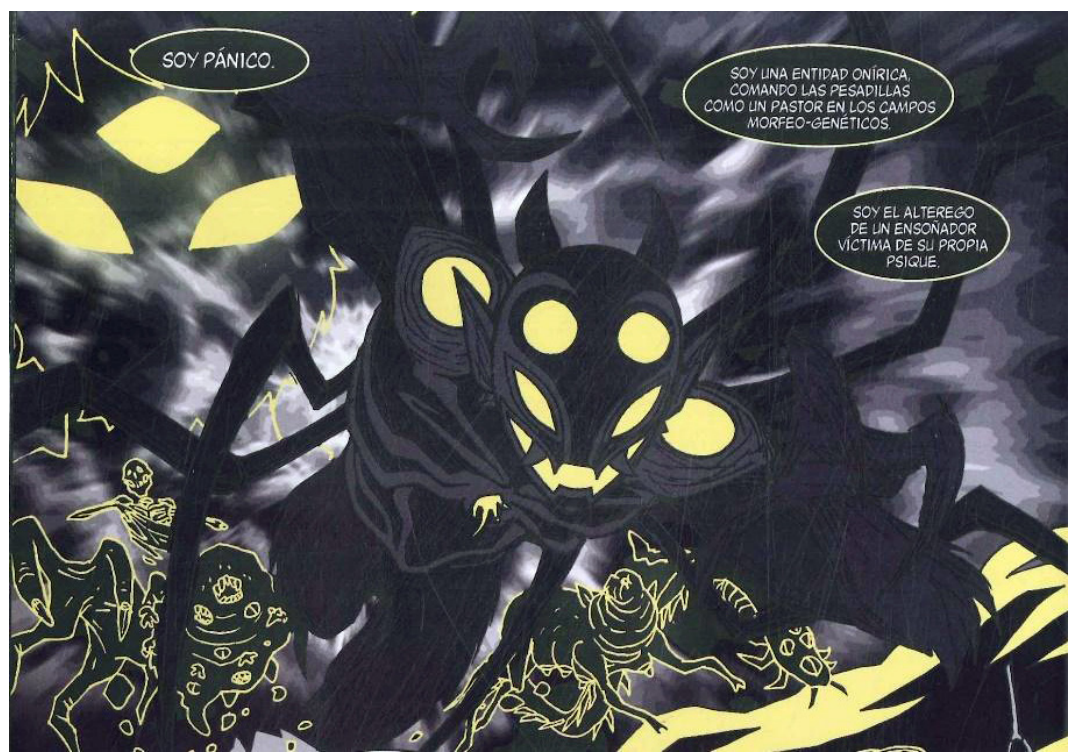

Figura 5. Vecchio, Sereno, 2016, p. 32. 
Los villanos de este primer libro reciben a su vez aportes de la tradición helénica. Pánico (del griego Пavıкós, -ท́, -óv), en el pulso 2, se vincula con la figura del dios Pan incluso en detalles del dibujo, como unos cuernos y cierta forma híbrida propia de lo "monstruoso" y del dios [FIG.5]. Pathos

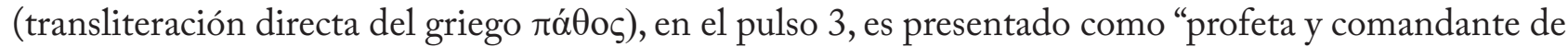
las huestes del odio", y se relaciona con la noción griega de "soportar y sufrir", que no siempre conlleva connotaciones negativas. Se asocia con "prueba", "algo que hay que transcurrir", y fonéticamente con la idea de aprendizaje, mathos, con la que se liga y que se refleja en el propio personaje al final de su recorrido, ya que de ese "dolor" aprenderá. ${ }^{33}$ Aquí Vecchio realiza un típico "movimiento griego": la personificación o deificación de un concepto abstracto (como pueden serlo Ananke, la "Necesidad", Týkhe, la "Fortuna", o Éris, la "Disputa", todos ellos sustantivos comunes abstractos antes de ganar sus divinas mayúsculas), ${ }^{34}$ que no había sido previamente personificado en la cultura griega y que a la vez le sirve para seguir indagando en el plano espiritual-emocional que desarrolla en la serie. ${ }^{35}$ En los pulsos 6 y 7, Fotofobos $\left(\varphi \tilde{\omega} \varsigma^{36}+\varphi o ́ \beta o \varsigma\right)$, el enemigo más poderoso y peligroso, recupera el doble valor del elemento compositivo -fobia, "aversión, rechazo", etimológicamente ligado a la idea de "miedo" y de "huida de la batalla". ${ }^{37} \mathrm{El}$ "miedo a la luz" o el "odio a la luz" se conjugan en este villano de estatus divino que se enfrenta con el ser superior de Sereno, el Selenita, en el cierre de esta primera aventura.

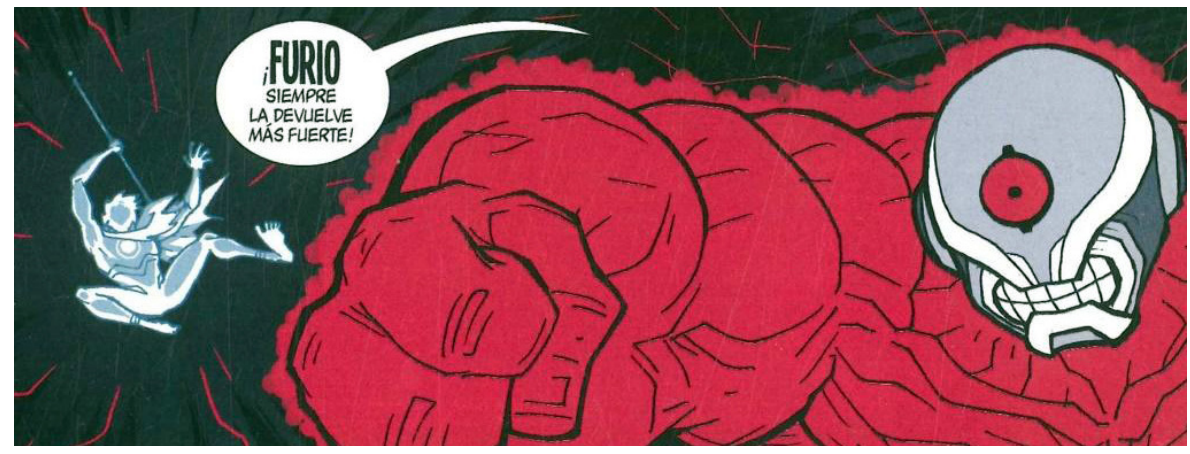

Figura 6. Vecchio, Sereno, 2016, p. 81.

33. Véase Esquilo, Agamenón v. 177, para esta idea de "aprendizaje por medio del dolor".

34. Véanse, por ejemplo, Smith (2011, p. 3). También López Monteagudo: "J. Duchemin señala que ya en la Theogonia de Hesíodo hay dos grandes categorías de personificaciones, una totalmente intelectual, resultado de una simple operación del espíritu, que es la de las ideas abstractas o más exactamente de las abstracciones personificadas, y otra constituida por las personificaciones de los elementos, ligada a las religiones primitivas o arcaicas. (...) Según H. Sichtermann, el progreso hacia la abstracción se documenta en el arte y en la poesía griegas ya desde el siglo VI a. C. y da como resultado la creación de nuevos personajes míticos a partir de los conceptos. Esta tendencia erudita pasa a los grandes maestros del clasicismo y ya en el helenismo aparecen representaciones de la Ilíada y de la Odisea, de la Sabiduría y de otras abstracciones en las concepciones artísticas" (1997, p. 336).

35. Páthos es un concepto importante también para la retórica: se vincula con el plano emocional (movere), con los "afectos", y puede apelar a sentimientos tanto positivos como negativos.

36. "Light, esp. daylight" (LSJ).

37. Fobos (Фóßos), de hecho, sí aparece personificado en la cultura griega ya desde Homero (Il. 4.40 y 5.739). Cfr. Grimal (1999, p. 205, s. v. Fobo). 
Párrafo aparte para Furio [FIG.6], en el pulso 6, que parece jugar -por medio de la inversión genérica- con la figura de las Furias romanas (asimiladas a las Erinias griegas) y que representa las "emociones tóxicas" (sintagma muy en boga hoy en día y encarnado aquí en una referencia clásica). Lo interesante es que gráficamente está resuelto como un cíclope: posee un solo ojo, un tamaño gigantesco y una fortaleza descomunal, y su enfurecimiento es proverbial. Como Odiseo, Sereno lo vence con bastante astucia y un poco de fuerza.

Por su parte, en el segundo volumen de la obra, Sereno $S$, se presenta un abordaje similar en el tratamiento de elementos del mundo clásico, es decir, un triple funcionamiento en los niveles narrativo ("mítico"), lingüístico e icónico, y se recurre a ellos como un verdadero método compositivo.

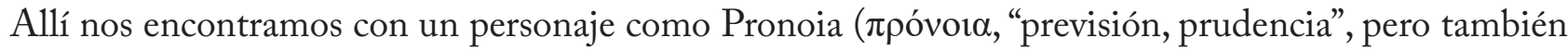
"propósito deliberado", "premeditación") o con el laboratorio Plutech ( $\pi \lambda$ oṽ $\tau$ os, "riqueza" + $\tau \dot{\varepsilon} \chi v \eta$,

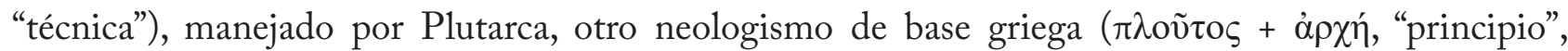
"poder", "autoridad", "magistratura"), que podría "traducirse" como "gobernante rico" o como "cada uno de los individuos que componen una plutarquía" (donde plutarquía sería el gobierno de los ricos; cfr.

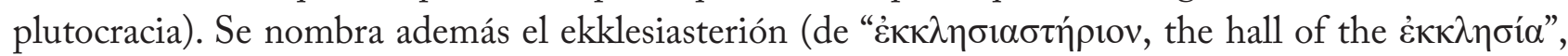
$L S J)$, cuya raíz remite a la democrática asamblea griega, pero de la que proviene a su vez el término español "Iglesia".

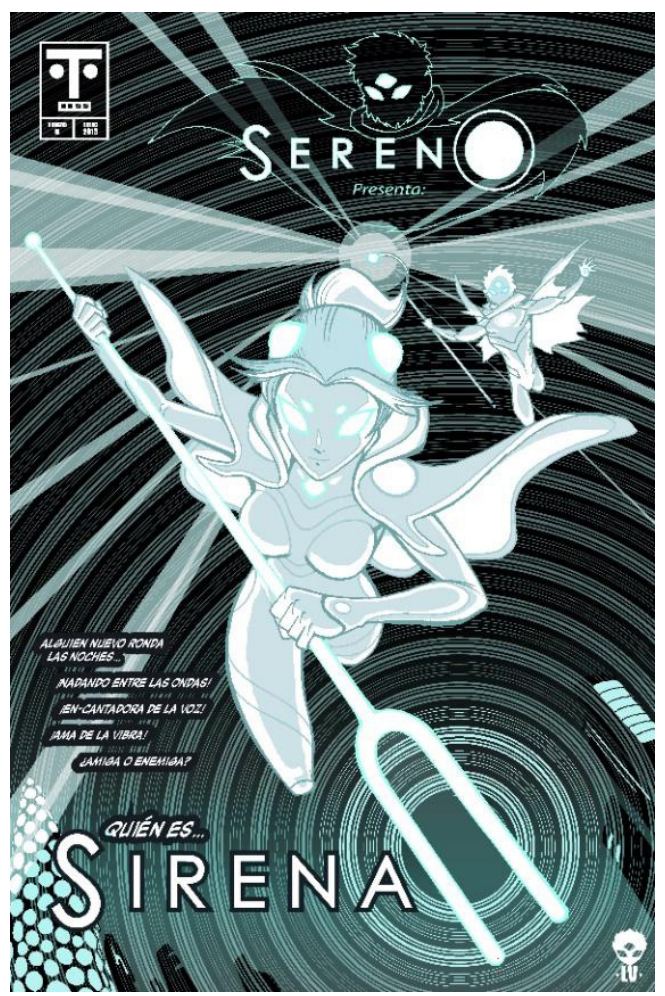

Figura 7. Vecchio, Sereno, 2021, pinup. 
Quisiera destacar también dos personajes aparecidos en los pinups de "Sereno presenta" (online): Sirena [FIG.7] y Épicx (léase /épike/, en lenguaje no binario) [FIG.8]. Sirena es presentada así: "Alguien nuevo ronda las noches. ¡Nadando entre las ondas! ¡En-cantadora de la voz! ¡Ama de la vibra! El misterio de la Sirena". Desde el dibujo y desde el nombre las similitudes con Sereno son patentes, como si se tratara de su versión femenina, pero se mantiene en la ambigüedad si es villana o heroína (el "rondar las noches" puede vincularla con el propio Sereno o con otros personajes "oscuros" o ambivalentes como Rufián). ${ }^{38}$ Las sirenas griegas son más bien presentadas como seres monstruosos y malignos que impiden la navegación segura a causa de su canto. La mención del nado remite a las sirenas medievales (mitad mujer y mitad pez), pero el dibujo la muestra en pleno vuelo, hecho que rescata la naturaleza alada de las sirenas homéricas o de su representación en los vasos griegos. Además, a semejanza de Sereno, porta una suerte de cetro o bastón, que en su caso recuerda al tridente de Poseidón (y también, dados sus poderes “musicales”, a un diapasón). ${ }^{39}$

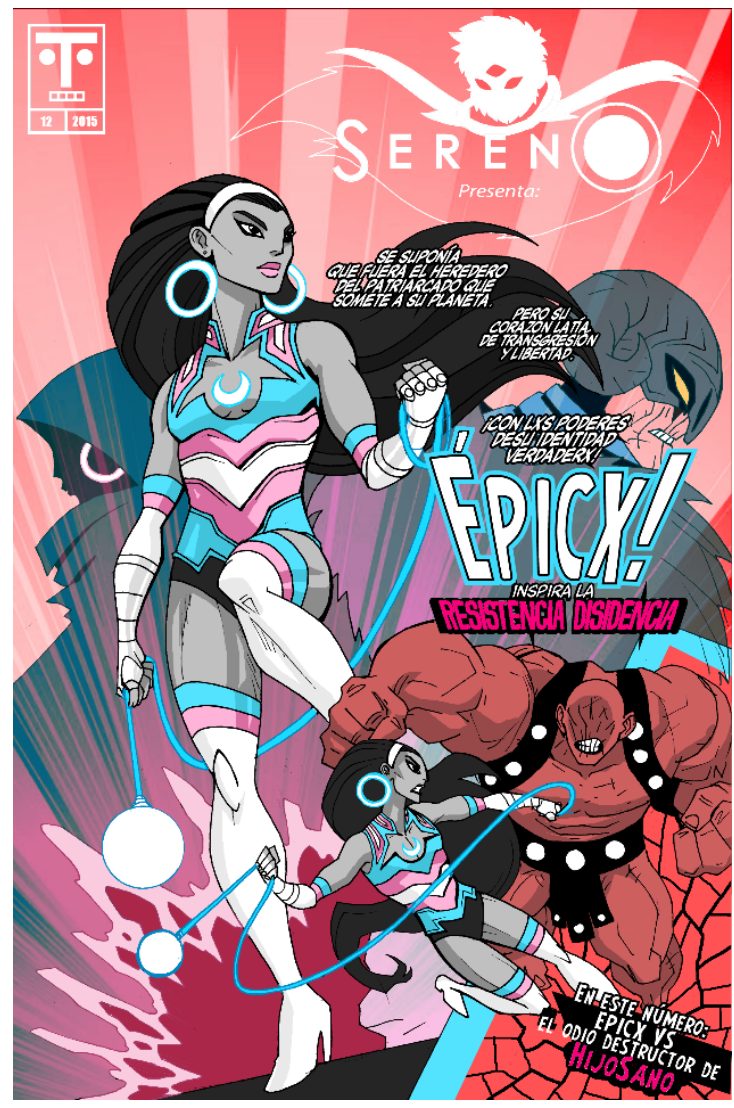

Figura 8. Vecchio, Sereno, 2021, pinup.

38. De todos modos, en el segundo volumen de la historia se la muestra luchando al lado de Sereno.

39. Hay aquí un doble juego: Sirena parece una variación de Sereno, pero en realidad supone un abrevar en la mitología, por lo que el resultado es un híbrido entre la figura original griega y una "versión" de un personaje nuevo. 


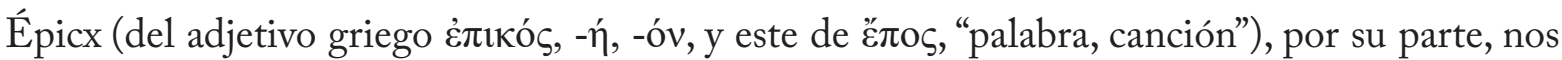
regala este avance de una posible historia:

Se suponía que fuera el heredero del patriarcado que somete a su planeta. Pero su corazón latía de transgresión y libertad. Con lxs poderes de su identidad verdaderx. Épicx! inspira la resistencia disidencia. En este número: Épicx vs el odio destructor de HijoSano. ${ }^{40}$

Por medio de este pinup (o, por qué no, un spinoff hiperconcentrado) ingresa en la serie -más explícitamente, porque ya está presente- la cuestión de la diversidad y en particular la representación de las personas transgénero. El personaje tiene ciertas reminiscencias de la amazona Wonder Woman tanto en la vestimenta cuanto en el "lazo" que porta, y quizás homenajea en parte también a la Lady Di trans de la novela Kriptonita de Leo Oyola (que realiza un movimiento similar al de Sereno, al plantearse como reinterpretación argentina de la norteamericana y superheroica Liga de la Justicia de la editorial DC Comics).

\section{Conclusiones}

En este recorrido hemos podido ver ciertos usos de una tradición clásica (casi exclusivamente la griega) por parte de Luciano Vecchio. Gran parte del trabajo ha estado dedicado a analizar la importancia de la Titánide Teia, que da nombre a la ciudad [FIG.2], como principio constructivo de la ficción de Sereno en relación con la luz que rodea al personaje y que emana de él. Esa apropiación o ese redescubrimiento de una figura divina un tanto oscura (pese a la luminosidad que representa) nos lleva a la idea de "originalidad" entendida como vuelta a los orígenes, idea cara a la Antigüedad. Pero también implica, por un lado, una búsqueda de originalidad en nuestros términos, ya que se evita por ejemplo la recurrente figura de Febo Apolo, que suele usarse cuando se quiere indicar lo luminoso o hacer una referencia al sol; por otro, una toma de posición, al "eclipsar" al dios con una deidad femenina y, de ese modo, volver a aludir al mundo femenino de Sailor Moon. ${ }^{41}$ Ese nombre aplicado a la ciudad se refuerza en diversos títulos de los pulsos con otras palabras provenientes del vocabulario griego y en conceptos que riegan el mundo ficcional de la historieta, siempre cruzados con referencias a otras culturas.

En cuanto a los personajes, más allá de los mencionados pinups de Sirena [FIG.6] y Épicx [FIG.8], los villanos más importantes como Pathos y Fotofobos se construyen recurriendo a términos griegos, pero, a la vez, a ese mecanismo de personificación de sustantivos abstractos típico de la cultura griega; algo semejante ocurre con Furio [FIG. 6], aunque en este caso con nombre de origen latino,

40. "HijoSano" remite a la vez a la formación de nombres de personajes típica del comic norteamericano (cfr. Darkseid) y al concepto de "hijo sano del patriarcado".

41. Cfr. García Jurado (2007, p. 188): "Los antiguos abren nuevas posibilidades a los modernos, pero éstos pueden modificar mediante sus lecturas y reescrituras la visión que tenemos de aquéllos. En definitiva, es posible estudiar la relación entre las literaturas antiguas y modernas desde presupuestos donde los autores modernos no son meros receptores, sino que tienen también mucho que decir acerca de los antiguos, dada su capacidad para reinterpretarlos y volver a contar la literatura grecolatina desde sus nuevas perspectivas históricas". 
que será personificado visualmente como un cíclope. Además, es un modo de reinterpretar cierta tradición de la historieta superheroica norteamericana que muchas veces se nutre de referencias o palabras de origen griego para crear no solo un "sabor épico", sino también personajes, muchas veces villanos (Agamemno de Mark Waid y Terry Dodson, Onomatopoeia de Kevin Smith y Phil Hester). Y todo este trabajo de (re)creación y (re)conceptualización se funde en diversos momentos, como es esperable en el lenguaje de la historieta, con la (re)presentación gráfica (la Titánide Teia [FIG.3 y FIG.4], un Sereno heleno [FIG.3], la guardia spartech [FIG.4]).

En conclusión, hemos visto cómo los elementos señalados han sido utilizados para construir de manera novedosa una ficción que se enmarca en el género superheroico y cómo, reinterpretados y resignificados creativamente, se han imbricado con la narración gráfica en sus distintos niveles.

\section{Referencias bibliográficas}

Carrión,J. (2017). Tradición y ruptura de las convenciones superheroicas en Sereno de Luciano Vecchio. Ponencia presentada en el Segundo Congreso Universitario de Historietas (16 y 17 de noviembre 2017), Facultad de Humanidades y Ciencias de la Educación de la Universidad Nacional de La Plata, Argentina. Inédito.

Espinosa Alarcón, A. (1981). Luciano. Obras I. Relatos verídicos. Madrid, Gredos.

Favaro, A. (2017). Más allá de la palabra. Transposiciones de la literatura argentina a la historieta. Buenos Aires, Biblos.

Ferro, G. (2016). Puesto a germinar. En El lapsus del jinete ciego. [disco compacto]. Buenos Aires, Costurera Carpintero.

García Jurado, F. (2007). ¿Por qué nació la juntura “Tradición Clásica”? Razones historiográficas para un concepto moderno. $C F C$ (EL), 27 (1), 161-192.

García Jurado, F. (2015). Tradición frente a Recepción Clásica: Historia frente a Estética, Autor frente a Lector. Noua Tellus, 33 (1), 9-37.

Grimal, P. (1999). Diccionario de mitología. Grecia y Roma. Buenos Aires, Paidós.

Hernández Reyes, A. (2008). Los mitos griegos en el manga japonés. En Castillo Pascual,M.J. (coord.), "Imagines". La Antigüedad en las Artes Escénicas y Visuales (pp. 633-644). Logroño, Universidad de la Rioja.

Hildebrandt, J. (16 de enero de 2019). Nuevos superhéroes argentinos. Comiqueando online. https://bit.ly/3fdJXvY.

Kovacs, G. y Marshall, C. (2011). Classics and Comics. Classical Presences. Oxford, Oxford University Press.

Kovacs, G. y Marshall, C. (eds.) (2015). Son of Classics and Comics. Classical Presences. Oxford, Oxford University Press. 
Liddell, H. y Scott, R. (1968). A Greek-English Lexicon. Oxford, Clarendon Press. (Original de 1843.)

López Monteagudo, G. (1997). Personificaciones alegóricas en mosaicos del Oriente y de Hispania: la representación de conceptos abstractos. Antigüedad y Cristianismo, XIV, 335-361.

Márquez, J. (2005). Envidia y política en la Antigua Grecia. España, Libros en Red.

Martignone,H. (15 de agosto de 2017). Páginas de la historieta argentina (1) - Sereno S. Sobre bistorieta. https://bit.ly/2WDnphR.

Morrison, G. (2012). Supergods. Héroes, mitos e historias del cómic. Madrid, Turner.

Ortega, A. (1984). Pindaro. Odas. Madrid, Gredos.

Oyola, L. (2013). Kryptonita. Buenos Aires, Random House.

Pabón, J. M. (1978). Vox. Diccionario manual griego-español. Barcelona, Bibliograf.

Sánchez Kutika, S. (16 de septiembre de 2016). Sereno, de Luciano Vecchio. Indie Hoy. https://bit.ly/2V8QocK.

Smith, A. (2011). Polis and Personification in Classical Athenian Art. Leiden/Boston, Brill.

Varona Codeso, P. (2007). Tucídides. El discurso fúnebre de Pericles. Madrid, Sequitur.

Vecchio, L. (2016). Sereno. Buenos Aires, Gutter Glitter.

Vecchio, L. (2017). Sereno S (webcomic). Totem comics. https://bit.ly/3rI7yKc.

*Hernán Martignone es Profesor, Licenciado y Doctor en Letras Clásicas por la Universidad de Buenos Aires. Enseña griego clásico en la Facultad de Filosofía y Letras (UBA) y latín en nivel medio (ILSE/CNBA). Escribió Historietas a diario. Las tiras cómicas argentinas de Mafalda a nuestros dias con Mariano Prunes (Buenos Aires, Libraria). Como guionista hizo historietas con dibujos de Lauri Fernández, Isidoro Reta y Diego Rey, entre otrxs.

RECIBIDO: 21/05/2021

ACEPTADO: 06/06/2021 